\title{
A novel frameshift GRN mutation results in frontotemporal lobar degeneration with a distinct clinical phenotype in two siblings: case report and literature review
}

Takashi Hosaka $^{1 \dagger}$, Kazuhiro Ishii ${ }^{1 *+}$, Takeshi Miura ${ }^{2,3}$, Naomi Mezaki ${ }^{2,3}$, Kensaku Kasuga $^{2}$, Takeshi Ikeuchi and Akira Tamaoka'

\begin{abstract}
Background: Progranulin gene (GRN) mutations are major causes of frontotemporal lobar degeneration. To date, 68 pathogenic GRN mutations have been identified. However, very few of these mutations have been reported in Asians. Moreover, some GRN mutations manifest with familial phenotypic heterogeneity. Here, we present a novel GRN mutation resulting in frontotemporal lobar degeneration with a distinct clinical phenotype, and we review reports of GRN mutations associated with familial phenotypic heterogeneity.

Case presentation: We describe the case of a 74-year-old woman with left frontotemporal lobe atrophy who presented with progressive anarthria and non-fluent aphasia. Her brother had been diagnosed with corticobasal syndrome (CBS) with right-hand limb-kinetic apraxia, aphasia, and a similar pattern of brain atrophy. Laboratory blood examinations did not reveal abnormalities that could have caused cognitive dysfunction. In the cerebrospinal fluid, cell counts and protein concentrations were within normal ranges, and concentrations of tau protein and phosphorylated tau protein were also normal. Since similar familial cases due to mutation of GRN and microtubule-associated protein tau gene (MAPT) were reported, we performed genetic analysis. No pathological mutations of MAPT were identified, but we identified a novel GRN frameshift mutation (c.1118_1119delCCinsG: p.Pro373ArgX37) that resulted in progranulin haploinsufficiency.

Conclusion: This is the first report of a GRN mutation associated with familial phenotypic heterogeneity in Japan. Literature review of GRN mutations associated with familial phenotypic heterogeneity revealed no tendency of mutation sites. The role of progranulin has been reported in this and other neurodegenerative diseases, and the analysis of GRN mutations may lead to the discovery of a new therapeutic target.
\end{abstract}

Keywords: Progranulin, Primary progressive aphasia, Corticobasal syndrome, Frontotemporal lobar degeneration, Phenotypic heterogeneity, Case report

\section{Background}

Frontotemporal lobar degeneration (FTLD) is characterized by degeneration of the frontal and temporal lobes, and presents as a clinically heterogeneous disease. The pathological classification of FTLD is based on the molecular features of the disease-associated inclusion-

\footnotetext{
* Correspondence: kazishii@md.tsukuba.ac.jp

${ }^{\dagger}$ Equal contributors

'Department of the Neurology, Division of Clinical Medicine, Faculty of Medicine, University of Tsukuba, 1-1-1 Ten'noudai, Tsukuba, Ibaraki 305-8575, Japan

Full list of author information is available at the end of the article
}

forming proteins: FTLD-tau, FTLD-TDP, FTLD-FUS, and FTLD-UPS. Clinically, FTLD is classified into two subsets: behavioral variant FTLD (bvFTLD) and primary progressive aphasia (PPA), the latter of which includes semantic dementia and progressive non-fluent aphasia. In addition, FTLD can be concomitant with corticobasal degeneration (CBD), progressive supranuclear palsy (PSP), and motor neuron disease (MND) [1].

Progranulin is widely expressed in the central nervous system and is involved in immunomodulation as well as cell growth and proliferation. Since the first demonstration of 
FTLD-associated progranulin gene $(G R N)$ mutation in $2006[2,3]$, more than 150 GRN mutations have been identified, including 68 pathogenic mutations. FTLD due to a GRN mutation is histopathologically characterized by ubiquitin-positive and TDP-43-positive inclusion bodies. While the most frequent clinical phenotype is bvFTLD, PPA and corticobasal syndrome (CBS) have also been reported [4-6]. There are also reports of clinical heterogeneity within a family $[7,8]$. In addition, FTLD due to a GRN mutation is rare in Asian individuals, with an incidence of $<1 \%$ in Asians compared to an incidence of $5-10 \%$ in Europeans $[9,10]$.

In this report, we present the case of a 74-year-old Japanese woman with left-side atrophy in the frontal and temporal lobes and symptoms of progressive anarthria and non-fluent aphasia. We identified the cause to be a novel frameshift mutation in GRN that caused progranulin haploinsufficiency.

\section{Case presentation}

A 74-year-old woman was referred to our hospital and admitted for progressive speech and language difficulties. The patient was unable to recall the names of things or persons and was unable to communicate with others for about 1 year prior to admission, though she was able to shop and do housework without difficulty. She had no significant medical history; however, regarding her family history, her elder brother had developed word-finding difficulty with verbal paraphasia and right-hand limbkinetic apraxia at the age of 62 years of age, and was diagnosed with CBS at 69 years of age. He had frontal lobe signs such as forced grasping, total aphasia, and right-limb kinetic apraxia; moreover, brain magnetic resonance imaging (MRI) demonstrated frontal and temporal lobar atrophy dominantly affecting the left side (Fig. 1a). The patient's brother and parents had passed away; therefore, we could not obtain their detailed clinical information.

Neurological findings indicated that our patient was lucid, but showed thought laziness. The cranial nerves, including those related to eye movement, were normal. The patient had normal muscle tonus and did not show muscle weakness or involuntary movement, but all extremity tendon reflexes were slightly increased. There was no evidence of sensory impairment or cerebellar ataxia. It was noted that speech required significant effort, was slow and non-fluent, and showed anarthria and aphasia. The patient's Mini-Mental Scale Examination score was 4/30.

Language function was assessed using the Western Aphasia Battery (WAB) Japanese edition once and SLTA (standard language test of aphasia) two times within 2 months. The scores of WAB subtests were as follows: spontaneous speech, 13 points; auditory verbal comprehension, 5.5 points; repetition, 0 points; naming, 0 points; reading, 4.3 points; writing, 2.2 points; praxis, 6.8 points; and construction, drawing, block design \& calculation, 6.6 points. Raven's score was 25/37 (average \pm standard deviation: $26.9 \pm 5.4$ ). Aphasia quotient was 36.8. The results of SLTA were similar to those of
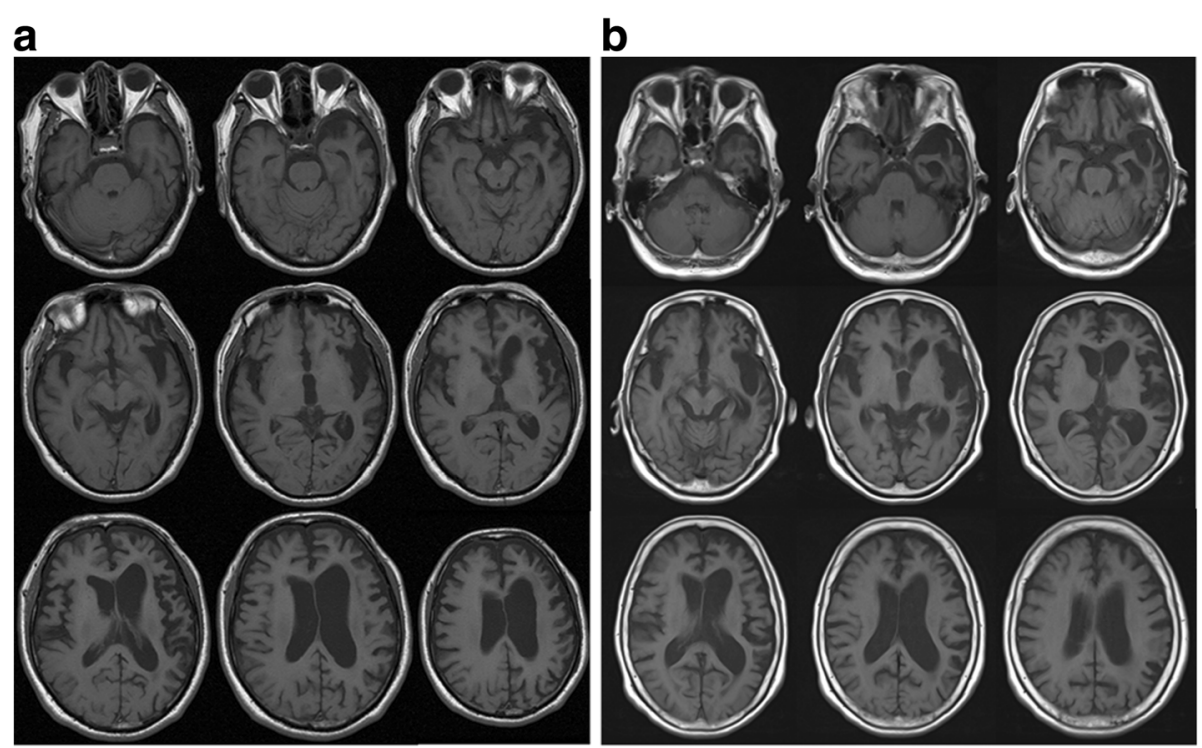

Fig. 1 Brain MRI (axial T1-weighted images) of the patient's brother (a) and the patient (b). a T1-weighted brain images of the patient's brother at 4 years after disease onset. Atrophy was predominantly observed in the left hemisphere affecting the frontotemporal lobes. b T1-weighted brain images of the patient at 1 year after disease onset. Similar to her brother, atrophy was predominantly observed in the left hemisphere affecting the frontal and temporal lobes 
WAB. Naming, writing, and repetition were impaired. However, auditory verbal comprehension and reading concerning words and short sentences were relatively preserved. Spatial perception and visual perception were also normal. Verbal comprehension via visual perception was approximately normal. Therefore, it is likely that auditory verbal comprehension was complemented by visual perception. Constructional dysfunction, limbkinetic apraxia, ideational apraxia, and motor apraxia were not observed. Laboratory blood examinations did not reveal any particular abnormalities that could have caused cognitive dysfunction. Cell counts and protein concentrations in the patient's cerebrospinal fluid were within normal ranges, and concentrations of tau protein $(282 \mathrm{pg} / \mathrm{mL})$ and phosphorylated tau protein $(31.3 \mathrm{pg} /$ $\mathrm{mL}$ or lower) were also normal. Brain MRI demonstrated cerebral atrophy dominantly affecting the left frontotemporal lobes (Fig. 1b).

Clinically, the main patient symptoms were difficulty in verbal expression and non-fluent aphasia in the absence of visual memory impairment or behavioral abnormalities. On this premise, the patient was diagnosed with PPA according to Mesulam's criteria [11]. Furthermore, the aphasia was classified as non-fluent progressive aphasia because, while speech itself required effort, the patient retained knowledge about objects and the ability to understand words. Brain MRI demonstrated cerebral cortical atrophy dominantly affecting the left frontal and temporal lobes, consistent with previous reports of non-fluent aphasia $[4,12]$. Thus, FTLD was diagnosed according to the patient's clinical symptoms. Since the patient's elder brother had been diagnosed with CBS, and similar familial cases of FTLD due to GRN and microtubule-associated protein tau gene (MAPT) mutations had been reported [13], we performed genetic analyses on the patient.

Genomic deoxyribonucleic acid (DNA) was extracted from peripheral leukocytes isolated from the patient. The exon/intron boundary of GRN was amplified by polymerase chain reaction (PCR) according to a previously reported method [2] and the PCR products were sequenced in both directions. Briefly, blood was collected into a PAXgene $^{\circ}$ RNA tube, total ribonucleic acid (RNA) was extracted from the sample, and cDNA was prepared from total RNA by a reverse transcriptase reaction. cDNA was then amplified by reverse transcriptase-polymerase chain reaction (RT-PCR) (forward primer: $5^{\prime}$-ACCCAGGCTGT GTGCTG-3'; reverse primer: $5^{\prime}$-GACAGCCTCTGGG ATTGGAC-3') and the gene expression of GRN was analyzed. Then, the amplified PCR product was extracted and its sequence was analyzed.

The genetic examination identified a novel mutation (c.1118_1119delCCinsG) in exon10 of GRN, which was thought to cause a frameshift mutation (p.Pro373ArgX38). No pathological mutations of MAPT were identified. The
GRN mRNA sequence was analyzed by RT-PCR; however, a mutant allele product was not detected, suggesting degradation of the mutant allele by the nonsense-mediated RNA decay system. Accordingly, haploinsufficiency due to reduced expression of progranulin was considered to be a possible pathogenic mechanism of FTLD in these cases (Fig. 2).

\section{Discussion and conclusions}

Various types of mutations including aberrant splicing, gene deletion, frameshift, and nonsense mutations of GRN have been reported. These mutations are known to cause familial FTLD via progranulin haploinsufficiency $[2,3]$. In the present case, our patient displayed PPA as a main symptom of progranulin haploinsufficiency due to a novel frameshift mutation of GRN. PPA, progressive difficulties with word recall and usage, and language comprehension impairments were apparent, whereas behavioral disinhibition, executive function, and memory impairments were not impaired in the early stages of disease (within 1 year after diagnosis). Other diseases known to cause PPA include FTLD, Alzheimer's disease (AD), CBS, and Creutzfeldt-Jakob disease (CJD) [11]; however, a large number of studies reporting a link between GRN mutations and PPA suggest that GRN mutations should always be considered in the differential diagnosis of PPA. Similar symptoms, neuropsychological profile, and neuroimaging findings have been reported in a monozygotic twin pair with a GRN mutation [14]. In contrast, in our case, the patient's brother presented distinct phenotypic characteristics (i.e., FTLD with PPA and CBS in the early stage). However, because the patient's brother had already passed away, we could not obtain sufficient information to perform a genetic

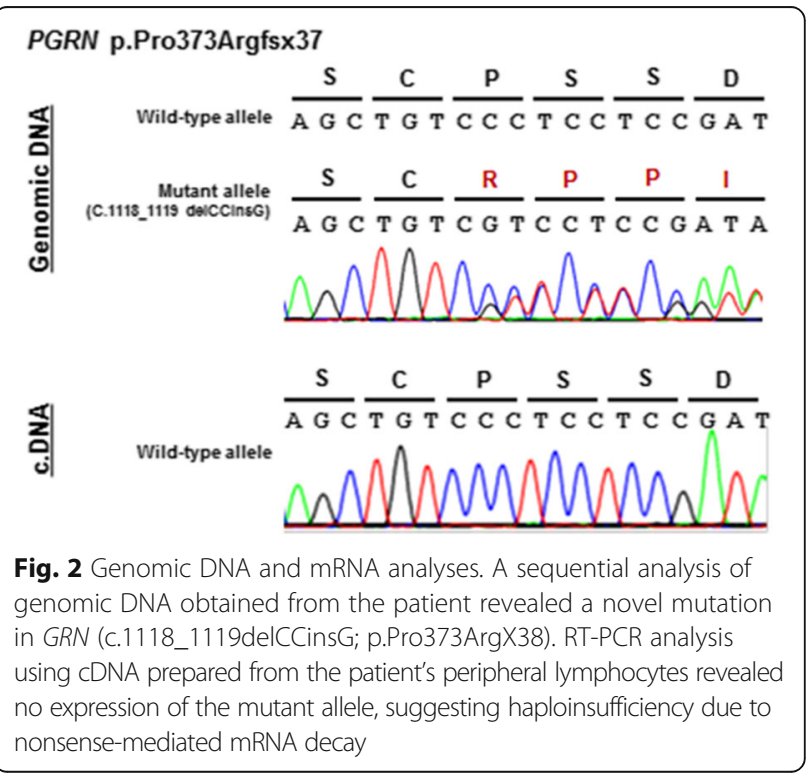


Table 1 Familial cases presenting with distinct clinical phenotypes

\begin{tabular}{|c|c|c|c|c|c|c|}
\hline Case & $\begin{array}{l}\text { Age onset; number of } \\
\text { patients }\end{array}$ & First symptom & Phenotype & Brain atrophy & Ethnic origin & GRN mutation \\
\hline \multirow{2}{*}{$\begin{array}{l}\text { Rovelet-Lecrux } \\
\text { et al., } 2008 \text { [15] }\end{array}$} & \multirow[t]{2}{*}{67,$77 ; 2$ patients } & Language dysfunction & PPA & \multirow[t]{2}{*}{ left $>$ right } & \multirow[t]{2}{*}{ French } & \multirow[t]{2}{*}{ g.95_4390del } \\
\hline & & Resting tremor & PD & & & \\
\hline \multirow[t]{2}{*}{$\begin{array}{l}\text { Spina et al., } \\
2007 \text { [13] }\end{array}$} & \multirow[t]{2}{*}{45,$73 ; 2$ patients } & $\begin{array}{l}\text { Involuntary arm } \\
\text { movement }\end{array}$ & CBS & \multirow[t]{2}{*}{ right $>$ left } & \multirow[t]{2}{*}{ N/A } & \multirow[t]{2}{*}{ g. $26 \mathrm{C}>\mathrm{A}$} \\
\hline & & Cognitive decline & $A D$ & & & \\
\hline \multirow[t]{2}{*}{$\begin{array}{l}\text { Beck et al., } \\
2008 \text { [4] }\end{array}$} & \multirow[t]{2}{*}{ 54-67; 10 patients } & Language dysfunction & PPA & $\begin{array}{l}\text { left }>\text { right } \\
(n=2)\end{array}$ & \multirow[t]{2}{*}{ United Kingdom } & \multirow[t]{2}{*}{ g.90_91insCTGC } \\
\hline & & Limb apraxia & CBS & $\begin{array}{l}\text { right }>\text { left } \\
(n=1)\end{array}$ & & \\
\hline \multirow{2}{*}{$\begin{array}{l}\text { Skoglund et al., } \\
2009 \text { [12] }\end{array}$} & \multirow[t]{2}{*}{$46-59 ; 10$ patients } & Language dysfunction & PPA & \multirow[t]{2}{*}{ N/A } & \multirow[t]{2}{*}{ Swedish } & \multirow[t]{2}{*}{ g.102delC } \\
\hline & & Limb apraxia & CBS & & & \\
\hline $\begin{array}{l}\text { Rademakers } \\
\text { et al., } 2007 \text { [16] }\end{array}$ & 62,$66 ; 2$ patients & N/A & FTLD, CBS & N/A & American & g. $3240 \mathrm{C}>\mathrm{T}$ \\
\hline \multirow{2}{*}{$\begin{array}{l}\text { Masellis et al., } \\
2006 \text { [17] }\end{array}$} & \multirow[t]{2}{*}{57,$62 ; 2$ patients } & Behavioral changes & FTLD & \multirow[t]{2}{*}{ right $>$ left } & \multirow{2}{*}{$\begin{array}{l}\text { Canadian family of } \\
\text { Chinese origin }\end{array}$} & \multirow[t]{2}{*}{ g.1637G > A } \\
\hline & & $\begin{array}{l}\text { Axial and extremity } \\
\text { rigidity }\end{array}$ & CBS & & & \\
\hline \multirow{3}{*}{$\begin{array}{l}\text { Leverenz et al., } \\
2007 \text { [18] }\end{array}$} & \multirow[t]{3}{*}{$35-69 ; 9$ patients } & Language dysfunction & FTLD & \multirow{3}{*}{$\begin{array}{l}\text { left }>\text { right } \\
(n=3) \\
\text { right }>\text { left } \\
(n=1)\end{array}$} & \multirow[t]{3}{*}{ American } & \multirow[t]{3}{*}{ g. $1871 A>G$} \\
\hline & & Anxiety, apathy & PPA & & & \\
\hline & & Parkinsonism & PD & & & \\
\hline \multirow{6}{*}{$\begin{array}{l}\text { López de Munain } \\
\text { et al., } 2008 \text { [19] }\end{array}$} & 53,$57 ; 2$ patients & N/A & FTLD, CBS & N/A & Basque Country & g. $1872 \mathrm{G}>\mathrm{A}$ \\
\hline & 51,$71 ; 2$ patients & N/A & FTLD, CBS & N/A & Basque Country & g.1873G > A \\
\hline & $65 ; 2$ patients & N/A & FTLD, CBS & N/A & Basque Country & g.1874G > A \\
\hline & $60 ; 2$ patients & N/A & FTLD, CBS & $\mathrm{N} / \mathrm{A}$ & Basque Country & g.1875G > A \\
\hline & 63-70; 4 patients & N/A & FTLD, CBS & N/A & Basque Country & g.1876G > A \\
\hline & $52 ; 2$ patients & N/A & FTLD, ALS & N/A & Basque Country & g.1877G > A \\
\hline Benussi et al., & 60-71; 5 patients & Language dysfunction & PPA & right $>$ left & Italian & g.1977_1980delCACT \\
\hline 2009 [5] & & Parkinsonism & CBS & & & \\
\hline Kelley et al., & N/A; 6 patients & N/A & FTLD, PD & symmetrical & American & g.2273_2274insTG \\
\hline & N/A; 6 patients & N/A & FTLD, PD & right $>$ left & American & g.2597delC \\
\hline $\begin{array}{l}\text { Pietroboni } \\
\text { et al., } 2011 \text { [7] }\end{array}$ & 47-79; 5 patients & $\begin{array}{l}\text { Memory impairment, } \\
\text { Acalculia }\end{array}$ & FTLD, AD & $\begin{array}{l}\text { right }>\text { left } \\
(n=1)\end{array}$ & Italian & g.63_64insC \\
\hline & & Language impairment & & $\begin{array}{l}\text { symmetrical } \\
(n=1) \\
\text { N/A }(n=3)\end{array}$ & & \\
\hline $\begin{array}{l}\text { Rossi et al., } \\
2011 \text { [8] }\end{array}$ & 47-80; 6 patients & $\begin{array}{l}\text { Behavioural } \\
\text { abnormality }\end{array}$ & $\begin{array}{l}\text { FTLD } \\
\text { Dementia }\end{array}$ & Left $>$ right & Italian & g.1761_1762delCA \\
\hline & & Language dysfunction & & & & \\
\hline & & Attention impairment & & & & \\
\hline The present case & 75,$62 ; 2$ patients & Language dysfunction & PPA & left > right & Japanese & g.1118_1119delCCinsG \\
\hline & & Limb apraxia & CBS & & & \\
\hline
\end{tabular}

$A D$ Alzheimer's disease, $A L S$ amyotrophic lateral sclerosis, $C B S$ corticobasal syndrome, FTLD frontotemporal lobar degeneration, GRN progranulin gene, N/A not available, $P D$ Parkinson's disease, PPA primary progressive aphasia

analysis. Table 1 provides a summary of known cases of GRN mutations that have been associated with familial phenotypic heterogeneity. The presence of familial phenotypic heterogeneity with respect to symptoms such as cognitive dysfunction and motor impairment has been reported in 17 families with GRN mutations [4-10, 12-19].
These studies reported significant variations in age of onset and mutation site, and motor neuron diseases were relatively uncommon. Families have also been reported with differing symptom laterality and different regions of brain atrophy. In a genetic analysis of 48 Japanese families with FTLD, PSP, or CBS [10], only one FTLD case with a GRN 
mutation was identified. Therefore, familial FTLD associated with GRN mutations is very rare. Furthermore, our report is the first to describe in detail distinct phenotypes within a family. Additional investigations of GRN mutations mediating different clinical phenotypes of neurodegeneration within a family are necessary.

As mentioned above, haploinsufficiency is thought to underlie the mechanism of GRN mutation-associated FTLD. Haploinsufficiency is a cause of autosomal genetic conditions when the protein expressed by a single allele is not sufficient to maintain its normal function (loss of function) [20]. On the other hand, in many autosomal dominant conditions, toxic gain of function or toxicity of excessive proteins are the cause of disease $[21,22]$. In fact, an approximate $50 \%$ decrease in mRNA and $33 \%$ decrease in progranulin protein was reported in one $G R N$ mutation carrier $[1,2]$. It has thus been suggested that an effective therapeutic strategy would be to increase progranulin levels in patients [1]. The relationship between GRN genetic variability and the risk of developing a neurodegenerative disease such as $A D$ or MND has been reported [1]. Yet, the exact functions of progranulin in the brain remain unclear, and its pathogenic involvement in neurodegenerative disorders is not known. Therefore, the accumulation of new cases of GRN mutations that display distinct clinical phenotypes within a family may be helpful not only for the elucidation of progranulin function, but also for the development of replacement therapies in FTLD and other neurodegenerative diseases due to GRN mutations.

\section{Abbreviations \\ AD: Alzheimer's disease; ALS: Amyotrophic lateral sclerosis; bVFTLD: Behavioral variant frontotemporal lobar degeneration; CBD: Corticobasal degeneration; CBS: Corticobasal syndrome; CJD: Creutzfeldt-Jakob disease; DNA: Deoxyribonucleic acid; FTLD: Frontotemporal lobar degeneration; GRN: Progranulin gene; MAPT: Microtubule-associated protein tau gene; MND: Motor neuron disease; MRI: Magnetic resonance imaging: PCR: Polymerase chain reaction; PD: Parkinson's disease; PPA: Primary progressive aphasia; PSP: Progressive supranuclear palsy; RNA: Ribonucleic acid; RT-PCR: Reverse transcriptase- polymerase chain reaction}

\section{Acknowledgements}

The authors thank the patient and her family for providing clinical data and allowing the publication of this case report. The authors would also like to thank Dr. N. Takegami for clinical assistance, and Ms. Y. Ishii, A. Kijima, S. Sugimoto and K. Takabe for technical assistance.

\section{Funding}

The genomic DNA and mRNA analyses in this study were supported by the Practical Research Project for Rare/Intractable diseases, Japan Agency for Medical Research and Development (AMED).

\section{Availability of data and materials}

All data generated or analyzed during this study are included in this published article.

\section{Authors' contributions}

$\mathrm{TH}$ and $\mathrm{KI}$ collected the clinical data, interpreted the data, and wrote the manuscript. KI recruited the patients and designed the manuscript. AT and $\mathrm{KI}$ performed the clinical data analysis and evaluation. TM, NM, KK, and TI analyzed genomic DNA and mRNA of the patient's blood sample. All authors read and approved the final version of manuscript.

Ethics approval and consent to participate

The authors declare that ethics approval was not required for this case report.

\section{Consent for publication}

Written informed consents for the patient and her brother were obtained from the patient's husband for publication of this Case Report and any accompanying images. A copy of the written consent is available for review by the Editor of this journal.

Competing interests

The authors declare that they have no competing interests.

\section{Publisher's Note}

Springer Nature remains neutral with regard to jurisdictional claims in published maps and institutional affiliations.

\section{Author details}

${ }^{1}$ Department of the Neurology, Division of Clinical Medicine, Faculty of Medicine, University of Tsukuba, 1-1-1 Ten'noudai, Tsukuba, Ibaraki 305-8575, Japan. ${ }^{2}$ Department of Molecular Genetics, Brain Research Institute, Niigata University, 1-757 Asahimachi, Niigata 951-8585, Japan. ${ }^{3}$ Department of Neurology, Brain Research Institute, Niigata University, 1-757 Asahimachi, Niigata 951-8585, Japan.

Received: 24 May 2017 Accepted: 1 September 2017

Published online: 15 September 2017

\section{References}

1. Petkau TL, Leavitt BR. Progranulin in neurodegenerative disease. Trends Neurosci. 2014:37:388-98.

2. Baker M, Mackenzie IR, Pickering-Brown SM, Gass J, Rademakers R, Lindholm $C_{1}$, et al. Mutations in progranulin cause tau-negative frontotemporal. dementia linked to chromosome 17. Nature. 2006;442:916-9.

3. Cruts M, Gijselinck I, van der Zee J, Engelborghs S, Wils H, Pirici D, et al. Null mutations in progranulin cause ubiquitin-positive frontotemporal dementia linked to chromosome 17q21. Nature. 2006;442:920-4.

4. Beck J, Rohrer JD, Campbell T, Isaacs A, Morrison KE, Goodall EF, et al. A distinct clinical, neuropsychological and radiological phenotype is associated with progranulin gene mutations in a large UK series. Brain. 2008;131:706-20.

5. Benussi L, Ghidoni R, Pegoiani E, Moretti DV, Zanetti O, Binetti G. Progranulin Leu271LeufsX10 is one of the most common FTLD and CBS associated mutations worldwide. Neurobiol Dis. 2009:33:379-85.

6. Kelley BJ, Haidar W, Boeve BF, Baker M, Graff-Radford NR, Krefft T, et al. Prominent phenotypic variability associated with mutations in Progranulin. Neurobiol Aging. 2009;30:739-51

7. Pietroboni AM, Fumagalli GG, Ghezzi L, Fenoglio C, Cortini F, Serpente M, et al. Phenotypic heterogeneity of the GRN Asp22fs mutation in a large Italian kindred. J Alzheimers Dis. 2011;24:253-9.

8. Rossi G, Piccoli E, Benussi L, Caso F, Redaelli V, Magnani G, et al. A novel progranulin mutation causing frontotemporal lobar degeneration with heterogeneous phenotypic expression. J Alzheimers Dis. 2011;23:7-12.

9. Rohrer JD, Guerreiro R, Vandrovcova J, Uphill J, Reiman D, Beck J, et al. The heritability and genetics of frontotemporal lobar degeneration. Neurology. 2009;73:1451-6.

10. Ogaki K, Li Y, Takanashi M, Ishikawa K, Kobayashi T, Nonaka T, et al. Analyses of the MAPT, PRGN, and C9orf72 mutations in Japanese patients with FTLD, PSP, and CBS. Parkinsonism Relat Disord. 2013;19:15-20.

11. Mesulam MM. Primary progressive aphasia. Ann Neurol. 2001;49:425-32.

12. Skoglund L, Brundin R, Olofsson T, Kalimo H, Ingvast S, Blom ES, et al. Frontotemporal dementia in a large Swedish family is caused by a progranulin null mutation. Neurogenetics. 2009;10:27-34.

13. Spina S, Murrell JR, Huey ED, Wassermann EM, Pietrini P, Grafman J, et al. Corticobasal syndrome associated with the A9D Progranulin mutation. J Neuropathol Exp Neurol. 2007:66:892-900.

14. McDade E, Boeve BF, Burrus TM, Boot BP, Kantarci K, Fields J, et al. Similar clinical and neuroimaging features in monozygotic twin pair with mutation in progranulin. Neurology. 2012;78:1245-9. 
15. Rovelet-Lecrux A, Deramecourt V, Legallic S, Maurage CA, Le Ber I, Brice A, et al. Deletion of the progranulin gene in patients with frontotemporal lobar degeneration or Parkinson disease. Neurobiol Dis. 2008;31:41-5.

16. Randemakers R, Baker M, Gass J, Adamson J, Huey ED, Momeni P, et al. Phenotype variability associated with progranulin haploinsufficiency in patients with the common 1477C>T(Arg493X) mutation: an international initiative. Lancet Neurol. 2007;6:857-68.

17. Masellis M, Momeni P, Meschino W, Heffner R Jr, Elder J, Sato C, et al. Novel splicing mutation in the progranulin gene causing familial corticobasal syndrome. Brain. 2006;129:3115-23.

18. Leverenz JB, Yu CE, Montine TJ, Steinbart E, Bekris LM, Zabetian C, et al. A novel progranulin mutation associated with variable clinical presentation and tau, TDP43 and alpha-synuclein pathology. Brain. 2007;130:1360-74.

19. López de Munain A, Alzualde A, Gorostidi A, Otaegui D, Ruiz-Martínez J, Indakoetxea B, et al. Mutations in progranulin gene: clinical, pathological, and ribonucleic acid expression findings. Biol Psychiatry. 2008;63:946-52.

20. Cook DL, Gerber AN, Tapscott SJ. Modeling stochastic gene expression: implications for haploinsufficiency. Proc Natl Acad Sci U S A. 1998;95:15641-6.

21. Davis JA, Naruse S, Chen H, Eckman C, Younkin S, Price DL. An Alzheimer's disease-linked PS1 variant rescues the developmental abnormalities of PS1deficient embryos. Neuron. 1998;20:603-9.

22. Qian S, Jiang P, Guan XM, Singh G, Trumbauer ME, Yu H. Mutant human presenilin 1 protects presenilin 1 null mouse against embryonic lethality and elevates Abeta1-42/43 expression. Neuron. 1998;20:611-7.

\section{Submit your next manuscript to BioMed Central and we will help you at every step:}

- We accept pre-submission inquiries

- Our selector tool helps you to find the most relevant journal

- We provide round the clock customer support

- Convenient online submission

- Thorough peer review

- Inclusion in PubMed and all major indexing services

- Maximum visibility for your research

Submit your manuscript at www.biomedcentral.com/submit 